\title{
Optimization of electrocoagulation process to treat grey wastewater in batch mode using response surface methodology
}

\author{
Thirugnanasambandham Karichappan ${ }^{1 \dagger}$, Sivakumar Venkatachalam ${ }^{2^{*}}$ and Prakash Maran Jeganathan ${ }^{3 \dagger}$
}

\begin{abstract}
Background: Discharge of grey wastewater into the ecological system causes the negative impact effect on receiving water bodies.

Methods: In this present study, electrocoagulation process (EC) was investigated to treat grey wastewater under different operating conditions such as initial pH (4-8), current density $\left(10-30 \mathrm{~mA} / \mathrm{cm}^{2}\right)$, electrode distance $(4-6 \mathrm{~cm})$ and electrolysis time (5-25 min) by using stainless steel (SS) anode in batch mode. Four factors with five levels Box-Behnken response surface design (BBD) was employed to optimize and investigate the effect of process variables on the responses such as total solids (TS), chemical oxygen demand (COD) and fecal coliform (FC) removal.
\end{abstract}

Results: The process variables showed significant effect on the electrocoagulation treatment process. The results were analyzed by Pareto analysis of variance (ANOVA) and second order polynomial models were developed in order to study the electrocoagulation process statistically. The optimal operating conditions were found to be: initial pH of 7, current density of $20 \mathrm{~mA} / \mathrm{cm}^{2}$, electrode distance of $5 \mathrm{~cm}$ and electrolysis time of $20 \mathrm{~min}$.

Conclusion: These results indicated that EC process can be scale up in large scale level to treat grey wastewater with high removal efficiency of TS, COD and FC.

Keywords: Electrocoagulation, Grey wastewater, Stainless steel electrodes, Box-Behnken design, Mathematical model

\section{Background}

With growing urbanization and rapid industrialization, the problem of the release of untreated wastewater into the ecosystem has been of increasing concern in many parts of the world. Since wastewaters can significantly contaminate the receiving water bodies, which cannot be ignored any longer. Therefore, the removal of toxic pollutants from wastewaters has recently become the subject of considerable interest due to more strict legislations introduced in many countries to control water pollution [1]. Grey wastewater has been recognized, one of the wastewater which includes water from baths, showers, hand basins, washing machines, dishwashers, kitchen sinks and constitutes $50-80 \%$ of the total household

\footnotetext{
* Correspondence: drvsivakumar@yahoo.com

${ }^{\dagger}$ Equal contributors

${ }^{2}$ Department of Food Technology, Kongu Engineering College, Perundurai Erode-638052, TN, India

Full list of author information is available at the end of the article
}

wastewater, but excludes streams from toilets. The discharges of untreated grey wastewater in the ecosystem have substantial impacts on the environment and human health [2]. Numerous studies have been conducted on the treatment of grey wastewater with different technologies which include UASB reactor [3], sequence batch reactor [4], membrane bioreactor [5] and vertical flow constructed wetlands [6]. These methods have been practiced as the prime method to treat grey wastewater for many years. However, these methods leads to a special problem of sludge handling, removal efficiency and their high costs limit their use in practice. So there is a critical need to develop more efficient and inexpensive method to treat grey wastewater.

In recent years, investigations have been focused on the treatment of grey wastewater using electrocoagulation (EC) process which offers several advantages including ease of operation, robustness to varying reaction

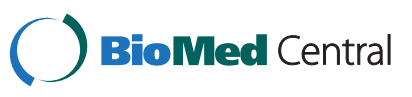


conditions and effluent types, less retention time, rapid sedimentation of the electrogenerated flocculants, less sludge production, and smaller space requirements and capital costs [7]. In addition, EC process has been applied to treat various wastewaters such as electroplating wastewaters [8], paper mill bleaching wastewater [9], chemical mechanical polishing wastewater [10], textile wastewater [11] and olive oil wastewater [12]. Extensive literature survey shows that none of researchers studied the optimization of the EC process using a stainless steel electrode to treat grey wastewater. To date, most studies on the optimization of wastewater treatment process have focused on the traditional one-factor-at-atime approach. However, this approach, which does not take into account cross effects from the factors considered, is time consuming and results in poor optimization results [13]. Response surface methodology (RSM) is a powerful statistical-based technique for modeling complex systems, evaluating the simultaneous effects of several factors, and thus searching optimum conditions for desirable responses [14]. RSM also generates a mathematical model that can be used to predict the response of a system to any new condition. However, still now, RSM has not been used as a modeling and optimization tool for EC process to treat grey wastewater in batch mode. Hence, in this study, Box-Behnken response surface design (BBD) coupled with Derringer's desired function methodology was used to optimize and investigate the influence of the key process variables of EC such as initial $\mathrm{pH}$, current density, electrode distance and electrolysis time (independent variables) on total solids (TS) removal, chemical oxygen demand (COD) removal and fecal coliforms (FC) removal (dependent variables).

\section{Materials and methods}

Wastewater sample and chemicals

The wastewater used in this study was collected from a tank containing a mixture of domestic wastewater in Erode, TamilNadu, southern India and were stored at $4^{\circ} \mathrm{C}$ prior to the experiments. The composition of the wastewater is shown in Table 1 . All reagents were of analytical grade and were used without further purification. Solutions were prepared at room temperature with deionised water.

Table 1 Composition of grey wastewater

\begin{tabular}{ll}
\hline \multicolumn{2}{c}{ Composition of grey wastewater } \\
\hline $\mathrm{pH}$ & 5.78 \\
$\mathrm{TS}(\mathrm{mg} / \mathrm{L})$ & 258 \\
$\mathrm{COD}(\mathrm{mg} / \mathrm{L})$ & 646 \\
Fecal coliform $\left(\mathrm{CFU} \times 10^{5} / \mathrm{mL}\right)$ & 2.2 \\
\hline
\end{tabular}

\section{Experimental setup and procedure}

Acrylic made tank having working volume of about $3 \mathrm{~L}$ was used to conduct the EC experiments. Stainless steel sheets of $33 \mathrm{~cm} \times 6 \mathrm{~cm}$ were used as electrodes for EC process. The gap between the anode and cathode was varied from 4 to $6 \mathrm{~cm}$. The entire electrode assembly was fitted on non-conducting wedges and hanged from the top of the electrocoagulation tank. The effective surface area of each electrode was $108 \mathrm{~cm}^{2}$. The assembly was connected to DC power source (Dolphin: 0-6 A and 0-30 V) to fix the desired current density. Schematic diagram of electrocoagulation reactor is shown in Figure 1. In each run, $1.6 \mathrm{~L}$ wastewater was placed into the reactor and all the runs were performed at constant stirring speed of $250 \mathrm{rpm}$ and $1 \mathrm{~g} / \mathrm{L}$ of $\mathrm{NaCl}$ as a supporting electrolyte. After the EC process, the power was switched off and the electrodes were dismantled. Before each run, impurities on the SS electrode surfaces were removed by dipping for $5 \mathrm{~min}$ in acetone solution. The treated wastewater collected at different time interval was filtered and used for analysis. Before analysis, treated wastewater was centrifuged at $6500 \mathrm{rpm}$ for $15 \mathrm{~min}$ (Remi R-24 Centrifuge, India) and supernatant liquid were collected for the determination of TS, COD and FC.

\section{Analytical methods}

Measurements of initial $\mathrm{pH}$, total solids (TS), chemical oxygen demand (COD) and fecal coliform (FC) were done in accordance with the standard methods reported in elsewhere [15]. The removal efficiency (R) was calculated using the following equation [16]

$$
\mathrm{R}(\%)=\frac{\mathrm{Y}_{0}-\mathrm{Y}}{\mathrm{Y}} \times 100
$$

where $Y_{0}$ and $Y$ represent are the initial and final value of TS, COD and FC.

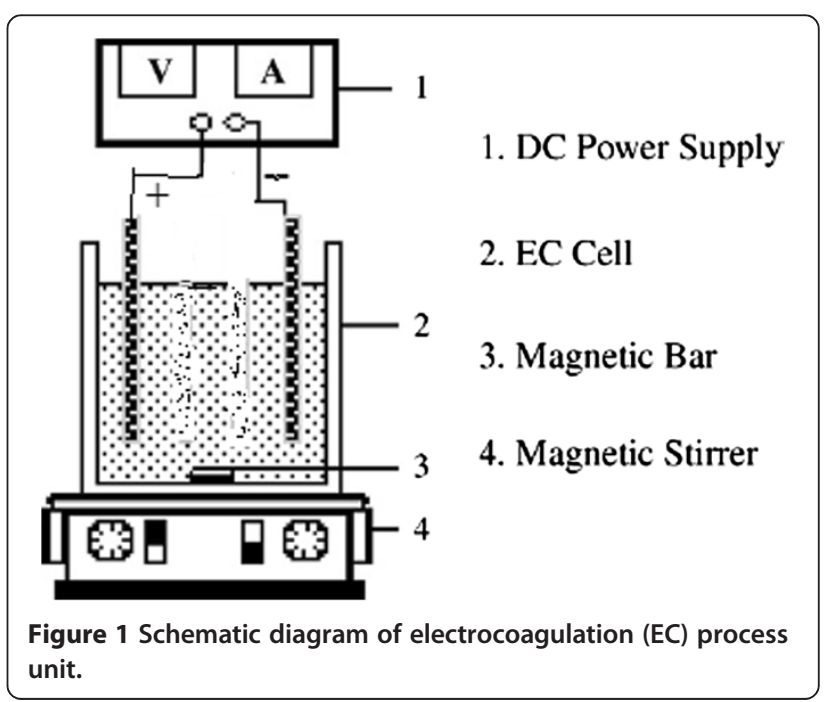




\section{Experimental design}

In this study, Box-Behnken response surface experimental design (BBD) with four factors at five levels was used to optimize and investigate the influence of process variables such as initial $\mathrm{pH}(4-8)$, current density (10$\left.30 \mathrm{~mA} / \mathrm{cm}^{2}\right)$, electrode distance $(4-6 \mathrm{~cm})$ and electrolysis time (5-25 $\mathrm{min}$ ) on the TS, COD and FC removal. Process variables and their ranges were determined based on the single factor experimental analysis. After selection of process (independent) variables and their ranges, experiments were established based on a BBD and the complete design consists of 29 experiments with five centre points.

A second-order polynomial equation was fitted to correlate the relationship between independent variables and responses, which accounts for variations caused by linear, quadratic and interactive effect of the process variables [17]. All the statistical analyses were done with the help of Stat ease Design Expert 8.0.7.1 statistical software package (Stat-Ease Inc., Minneapolis, USA). The details of methodology used for analyzing the experimental data and model are given in elsewhere [18].

\section{Results and discussions}

Electrocoagulation process using stainless steel electrodes to treat gery wastewater was carried out at different initial $\mathrm{pH}$, current density, electrode distance and electrolysis time to investigate the removal efficiency of TS, COD and FC. In this study, four factors with five levels BBD was used to evaluate the effect and optimize the process variables on the responses. A total number of 29 batch experiments including five centre points were carried

Table 2 Box-Behnken experimental design matrix with experimental and predicted response values

\begin{tabular}{|c|c|c|c|c|c|c|}
\hline Initial pH $\left(\mathrm{X}_{1}\right)$ & Current density $\left(\mathrm{X}_{2}\right)$ & Electrode distance $\left(\mathrm{X}_{3}\right)$ & Electrolysis time $\left(\mathrm{X}_{4}\right)$ & TS removal $\left(\mathrm{Y}_{1}\right)$ & COD removal $\left(\mathrm{Y}_{2}\right)$ & FC removal $\left(Y_{3}\right)$ \\
\hline 8 & 30 & 5 & 15 & 74.69 & 69.54 & 77.58 \\
\hline 4 & 30 & 5 & 15 & 55.78 & 48.58 & 54.36 \\
\hline 6 & 30 & 5 & 5 & 48.68 & 41.58 & 45.68 \\
\hline 4 & 20 & 6 & 15 & 30.75 & 29.58 & 32.58 \\
\hline 6 & 20 & 5 & 15 & 92.56 & 88.65 & 90.56 \\
\hline 6 & 30 & 5 & 25 & 95.65 & 90.54 & 91.05 \\
\hline 6 & 20 & 5 & 15 & 92.56 & 88.65 & 90.56 \\
\hline 6 & 20 & 4 & 25 & 95.56 & 92.56 & 93.56 \\
\hline 6 & 10 & 6 & 15 & 40.78 & 36.98 & 43.58 \\
\hline 4 & 10 & 5 & 15 & 21.56 & 18.65 & 26.54 \\
\hline 6 & 30 & 4 & 15 & 97.56 & 93.68 & 95.96 \\
\hline 6 & 10 & 5 & 25 & 67.94 & 64.28 & 62.58 \\
\hline 6 & 30 & 6 & 15 & 63.04 & 57.68 & 65.58 \\
\hline 6 & 20 & 5 & 15 & 92.56 & 88.65 & 90.56 \\
\hline 8 & 10 & 5 & 15 & 45.36 & 39.64 & 41.58 \\
\hline 6 & 20 & 6 & 25 & 70.14 & 66.76 & 72.65 \\
\hline 8 & 20 & 5 & 25 & 78.95 & 71.08 & 72.65 \\
\hline 8 & 20 & 4 & 15 & 82.36 & 78.91 & 81.64 \\
\hline 8 & 20 & 6 & 15 & 37.15 & 36.54 & 40.56 \\
\hline 6 & 10 & 4 & 15 & 49.56 & 40.98 & 45.65 \\
\hline 6 & 20 & 4 & 5 & 35.24 & 29.38 & 37.28 \\
\hline 6 & 20 & 5 & 15 & 92.56 & 88.65 & 90.56 \\
\hline 4 & 20 & 4 & 15 & 36.28 & 31.58 & 34.58 \\
\hline 6 & 10 & 5 & 5 & 18.68 & 16.89 & 22.56 \\
\hline 8 & 20 & 5 & 5 & 21.56 & 18.64 & 24.65 \\
\hline 6 & 20 & 6 & 5 & 12.56 & 10.58 & 15.65 \\
\hline 4 & 20 & 5 & 5 & 12.63 & 11.58 & 17.58 \\
\hline 4 & 20 & 5 & 25 & 52.65 & 48.65 & 55.47 \\
\hline 6 & 20 & 5 & 15 & 92.56 & 88.65 & 90.56 \\
\hline
\end{tabular}


Table 3 Model summary statistics tested for the responses

\begin{tabular}{cccccc}
\hline \multicolumn{6}{c}{ Model summary statistics } \\
\hline Std. Dev. & $\mathbf{R}^{\mathbf{2}}$ & Adjusted $\mathbf{R}^{2}$ & Predicted $\mathbf{R}^{\mathbf{2}}$ & PRESS & Remarks \\
\hline Total solids removal & & & & \\
\hline 19.1689 & 0.6177 & 0.5539 & 0.5223 & 11017.7 & \\
21.3110 & 0.6456 & 0.4487 & 0.3755 & 14403.9 & \\
3.1819 & 0.9939 & 0.9877 & 0.9646 & 816.4340 & Suggested \\
0.7371 & 0.9999 & 0.9993 & 0.9796 & 469.4592 & Aliased \\
\hline Chemical oxygen demand removal & & & \\
\hline 19.3375 & 0.5970 & 0.5298 & 0.4959 & 11224.9 & \\
21.3946 & 0.6300 & 0.4244 & 0.3511 & 14449.5 & \\
4.4728 & 0.9874 & 0.9748 & 0.9276 & 1613.2875 & Suggested \\
1.5086 & 0.9994 & 0.9971 & 0.9117 & 1966.4244 & Aliased \\
\hline Fecal coliform removal & & & & \\
\hline 18.3127 & 0.5985 & 0.5316 & 0.4954 & 10114.4 & \\
20.2988 & 0.6300 & 0.4245 & 0.3381 & 13267.6 & \\
4.8198 & 0.9838 & 0.9676 & 0.9065 & 1873.3270 & Suggested \\
1.0705 & 0.9997 & 0.9984 & 0.9506 & 990.1164 & Aliased \\
\hline
\end{tabular}

out in triplicates using statistically deigned experiments and the results are shown in Table 2.

\section{Selection of suitable mathematical model}

The experimental data was analyzed by model summary statistics in order to obtain regression models and decide about the adequacy of various models (linear, interactive, quadratic and cubic) to represent the EC process significantly. The results are listed in Table 3. From the Table 3, it was found that, linear and interactive (2FI) models shows lower coefficient of determination $\left(R^{2}\right)$, adjusted $-\mathrm{R}^{2}$, predicted $-\mathrm{R}^{2}$ and also having high $p$-values, when compared with quadratic model. Cubic model was found to be aliased. Therefore the quadratic model is chosen to describe the effects of operating variables on the EC process to treat grey wastewater [19]. Further more, analysis of variance (ANOVA) is also used to check the adequacy of quadratic model.

\section{Mathematical model fitting}

The results obtained from BBD experiments were evaluated by multiple regression analysis method for EC process. An empirical relationship between the response and independent variables has been expressed by a second-order polynomial equation with interaction terms was fitted between the experimental results obtained on the basis of BBD, which will help to predict the efficiency of EC process in different sets of combinations. Three empirical models were developed to understand the interactive correlation between the responses and process variables. The final model obtained in terms of coded factors is given below

$$
\begin{aligned}
Y_{1}= & 92.56+10.87 X_{1}+15.96 X_{2}-1.1 .85 X_{3} \\
& +25.96 X_{4}-1.22 X_{1} X_{2}-9.92 X_{1} X_{3}+4.34 X_{1} X_{4} \\
& -6.44 X_{2} X_{3}-0.57 X_{2} X_{4}-0.69 X_{3} X_{4}-29.44 X_{1}^{2} \\
& -13.25 X_{2}^{2}-16.79 X_{3}^{2}-21.88 X_{4}^{2} \\
Y_{2}= & 88.65+10.48 X_{1}+15.35 X_{2}-10.75 X_{3} \\
& +25.44 X_{4}-(7.500 E-0.003) X_{1} X_{2}-10.09 X_{1} X_{3} \\
& +3.84 X_{1} X_{4}-8.00 X_{2} X_{3}+0.39 X_{2} X_{4}-1.75 X_{3} X_{4} \\
& -29.16 X_{1}^{2}-14.65 X_{2}^{2}-16.38 X_{3}^{2}-21.71 X_{4}^{2} \\
& \\
Y_{3}= & 90.56+9.80 X_{1}+15.64 X_{2}-9.84 X_{3}+23.71 X_{4} \\
& +2.04 X_{1} X_{2}-9.77 X_{1} X_{3}+2.53 X_{1} X_{4}-7.08 X_{2} X_{3} \\
& +1.34 X_{2} X_{4}+0.18 X_{3} X_{4}-27.46 X_{1}^{2}-13.34 X_{2}^{2} \\
& -1.5 .02 X_{3}^{2}-21.01 X_{4}^{2}
\end{aligned}
$$

where, $Y_{1}, Y_{2}$ and $Y_{3}$ are percentage of TS, COD, FC removal ; $\mathrm{X}_{1}, \mathrm{X}_{2}, \mathrm{X}_{3}$ and $\mathrm{X}_{4}$ are initial $\mathrm{pH}$, current density, electrode distance and electrolysis time respectively.

\section{Adequacy of developed models}

The adequacy of models was evaluated by constructing diagnostic plots such as predicted versus actual plots
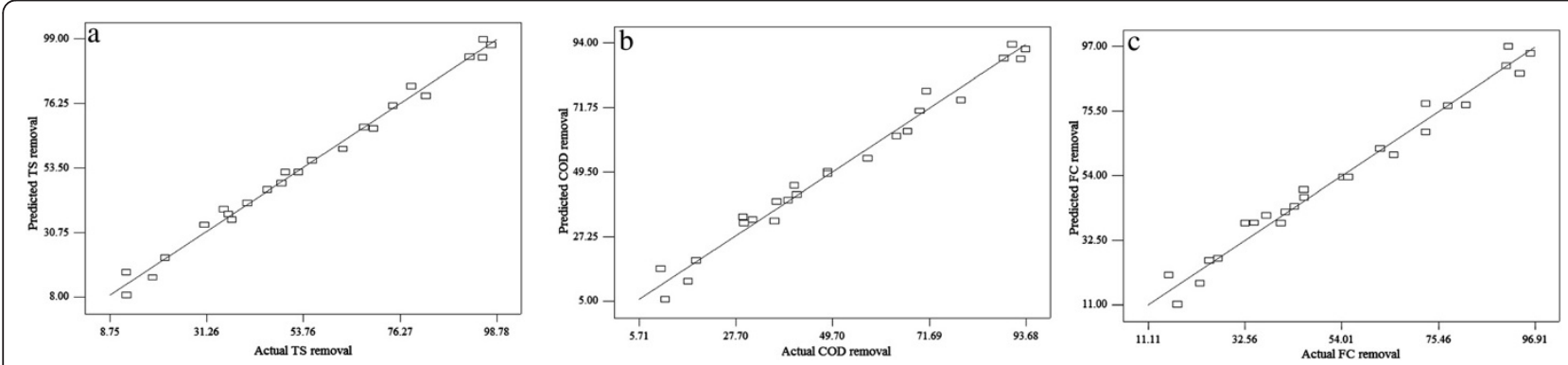

Figure 2 Actual versus predicted plots for the model adequacy testing. (a) TS removal (b) COD removal (c) FC removal. 
Table 4 ANOVA analysis and statistical parameters of the responses

\begin{tabular}{|c|c|c|c|c|c|c|c|c|c|}
\hline \multirow[t]{2}{*}{ Sources } & \multicolumn{3}{|c|}{ TS removal } & \multicolumn{3}{|c|}{ COD removal } & \multicolumn{3}{|c|}{ FC removal } \\
\hline & Mean square & F-value & p-value & Mean square & F-value & p-value & Mean square & F-value & p-value \\
\hline Model & 1637.35 & 161.72 & $<0.0001$ & 1570.57 & 78.50 & $<0.0001$ & 1408.64 & 60.64 & $<0.0001$ \\
\hline $\mathrm{X} 1$ & 1417.45 & 140.00 & $<0.0001$ & 1317.34 & 65.85 & $<0.0001$ & 1151.50 & 49.57 & $<0.0001$ \\
\hline$\times 2$ & 3056.66 & 301.91 & $<0.0001$ & 2826.86 & 141.30 & $<0.0001$ & 2936.57 & 126.41 & $<0.0001$ \\
\hline X3 & 1683.65 & 166.30 & $<0.0001$ & 1386.11 & 69.28 & $<0.0001$ & 1161.71 & 50.01 & $<0.0001$ \\
\hline$X 4$ & 8088.10 & 798.87 & $<0.0001$ & 7763.27 & 388.05 & $<0.0001$ & 6747.87 & 290.47 & $<0.0001$ \\
\hline$x_{1} x_{2}$ & 5.98 & 0.59 & 0.4550 & 0.00 & 0.00 & 0.9974 & 16.73 & 0.72 & 0.4104 \\
\hline$x_{1} x_{3}$ & 393.63 & 38.88 & $<0.0001$ & 407.43 & 20.37 & 0.0005 & 381.81 & 16.44 & 0.0012 \\
\hline$X_{1} X_{4}$ & 75.43 & 7.45 & 0.0163 & 59.06 & 2.95 & 0.1078 & 25.55 & 1.10 & 0.3120 \\
\hline$x_{2} x_{3}$ & 165.64 & 16.36 & 0.0012 & 256.00 & 12.80 & 0.0030 & 200.36 & 8.62 & 0.0108 \\
\hline$x_{2} X_{4}$ & 1.31 & 0.13 & 0.7243 & 0.62 & 0.03 & 0.8632 & 7.16 & 0.31 & 0.5877 \\
\hline$X_{3} X_{4}$ & 1.88 & 0.19 & 0.6733 & 12.25 & 0.61 & 0.4470 & 0.13 & 0.01 & 0.9415 \\
\hline$x_{1}^{2}$ & 5623.68 & 555.46 & $<0.0001$ & 5514.08 & 275.62 & $<0.0001$ & 4889.96 & 210.50 & $<0.0001$ \\
\hline$X_{2}^{2}$ & 1138.71 & 112.47 & $<0.0001$ & 1392.15 & 69.59 & $<0.0001$ & 1154.38 & 49.69 & $<0.0001$ \\
\hline$X_{3}^{2}$ & 1827.93 & 180.55 & $<0.0001$ & 1739.56 & 86.95 & $<0.0001$ & 1463.19 & 62.99 & $<0.0001$ \\
\hline$x_{4}^{2}$ & 3105.19 & 306.70 & $<0.0001$ & 3057.94 & 152.85 & $<0.0001$ & 2862.70 & 123.23 & $<0.0001$ \\
\hline Residual & \multicolumn{3}{|c|}{10.12} & \multicolumn{3}{|c|}{20.01} & \multicolumn{3}{|c|}{23.23} \\
\hline CV\% & \multicolumn{3}{|c|}{5.4} & \multicolumn{3}{|c|}{8.17} & \multicolumn{3}{|c|}{8.2} \\
\hline AP & \multicolumn{3}{|c|}{39.43} & \multicolumn{3}{|c|}{27.27} & \multicolumn{3}{|c|}{24.75} \\
\hline
\end{tabular}

for xthe experimental data obtained from this study and it is shown in Figure 2. From the Figure 2(a-c), it is observed that, the data points on this plot lie very close to the diagonal line, because residuals for the prediction of each response is minimum. Moreover, ANOVA results (Table 4) was also generated to check the adequacy of developed models which shows low $\mathrm{CV}$, AP value and acceptable mean square, F- value and p-value for individual and interactive effects [20]. These results indicated a good adequate agreement between experimental data and the data predicted by the developed models.

\section{Effect of process variables}

Three dimensional (3D) response surface plots are plotted using developed mathematical models (Equations 2,3,4) in order to study the individual and interactive effect among the process variables on the responses and also used to determine the optimal condition of each factor for maximum removal efficiency of TS, COD and FC.

\section{Effect of initial $\mathrm{pH}$}

It has been established that the intial $\mathrm{pH}$ is an important parameter influencing the performance of the EC process. To examine its effect, the wastewater sample

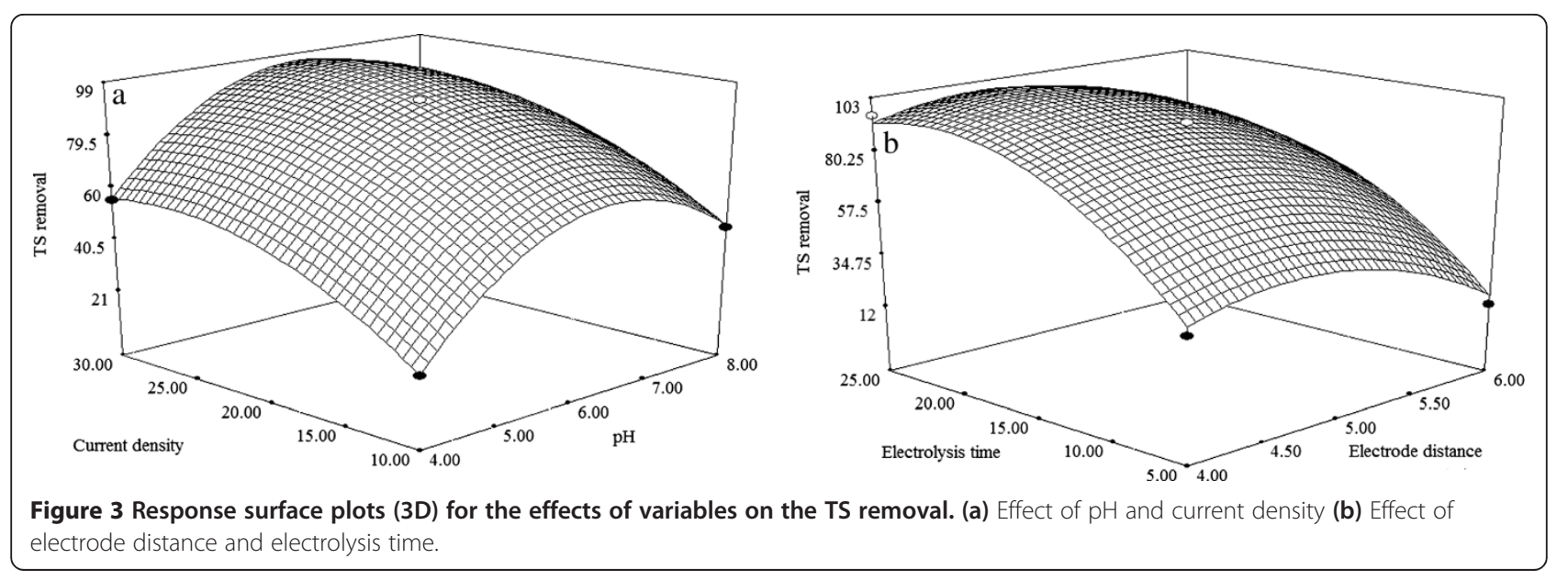



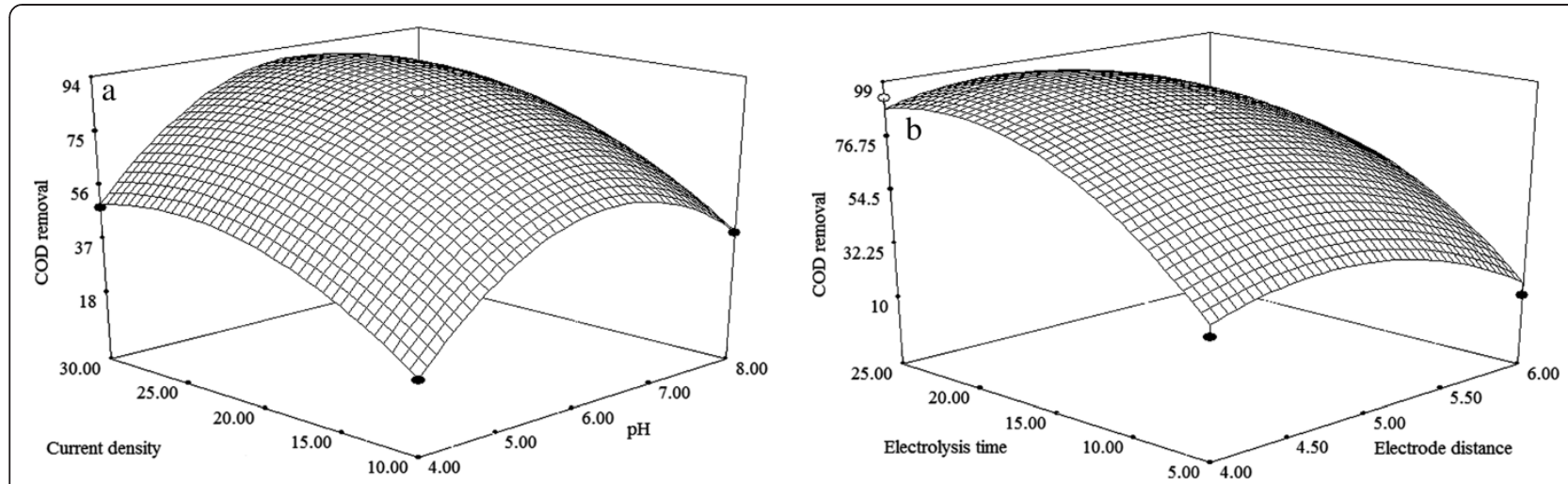

Figure 4 Response surface plots (3D) for the effects of variables on the COD removal. (a) Effect of pH and current density (b) Effect of electrode distance and electrolysis time.

was adjusted to a desired $\mathrm{pH}$ for each experiment by using sodium hydroxide or Hydrochloric acid. From the results (Figures 3a, 4a, 5a), it was observed that, the removal efficiency of TS, COD and FC was increased linearly with increasing initial $\mathrm{pH}$ from 4-6. This is mainly due to the fact that, when $\mathrm{pH}$ is within the range of 5.0-7.0, the formation of amorphous $M$ $(\mathrm{OH})_{3}$ species is predominant. The freshly formed amorphous $\mathrm{M}(\mathrm{OH})_{3}$ species has large surface area, which are beneficial for a removal of the TS,COD and FC via a sweep coagulation followed by precipitation mechanism. However, initial $\mathrm{pH}$ beyond 6 resulted in lower removal efficiencies was noticed due to the formation of monomeric $\mathrm{M}(\mathrm{OH})_{4}{ }^{-}$species [9].

\section{Effect of current density}

Current density is one of the important factor influence the electrocoagulation process. From the results (Figures 3a, 4a, 5a), it is found that, the removal efficiency of TS, COD and FC are increased rapidly upto current density of $20 \mathrm{~mA} / \mathrm{cm}^{2}$. This is explained the fact that, the coagulant production on the anode and cathode increases while increase the current density. Therefore, there is an increase in metal hydroxide $\left(\mathrm{M}(\mathrm{OH})_{3}\right)$ flocks formation in the reactor and hence theimprovement in the removal efficiencies. But, at higher current density $\left(25-30 \mathrm{~mA} / \mathrm{cm}^{2}\right)$, the removal of TS, COD and FC are almost constant [21]. Similar results were also noticed for treatment of paper mill bleaching wastewater using EC process [9].

\section{Effect of electrode distance}

To examine the effect of electrode distance on the EC process, experiments were conducted. From the results (Figures $3 \mathrm{~b}, 4 \mathrm{~b}, 5 \mathrm{~b}$ ), it is observed that, removal efficiency of TS, COD and FC are increased with the increasing electrode distance upto $5 \mathrm{~cm}$. At minimum inter electrode distance the resistance for current flow in the reactor is lower that facilitates the EC process for enhanced removal of TS, COD and FC. But, beyond $5 \mathrm{~cm}$ of electrode distance shows the decrease in removal efficiency of TS, COD and FC. This is due to the formation of ohmic loses which in turn inhibits the production of $\mathrm{M}$ $(\mathrm{OH})_{3}$ flocs, thus the removal of TS, COD and FC gets decreased [22].

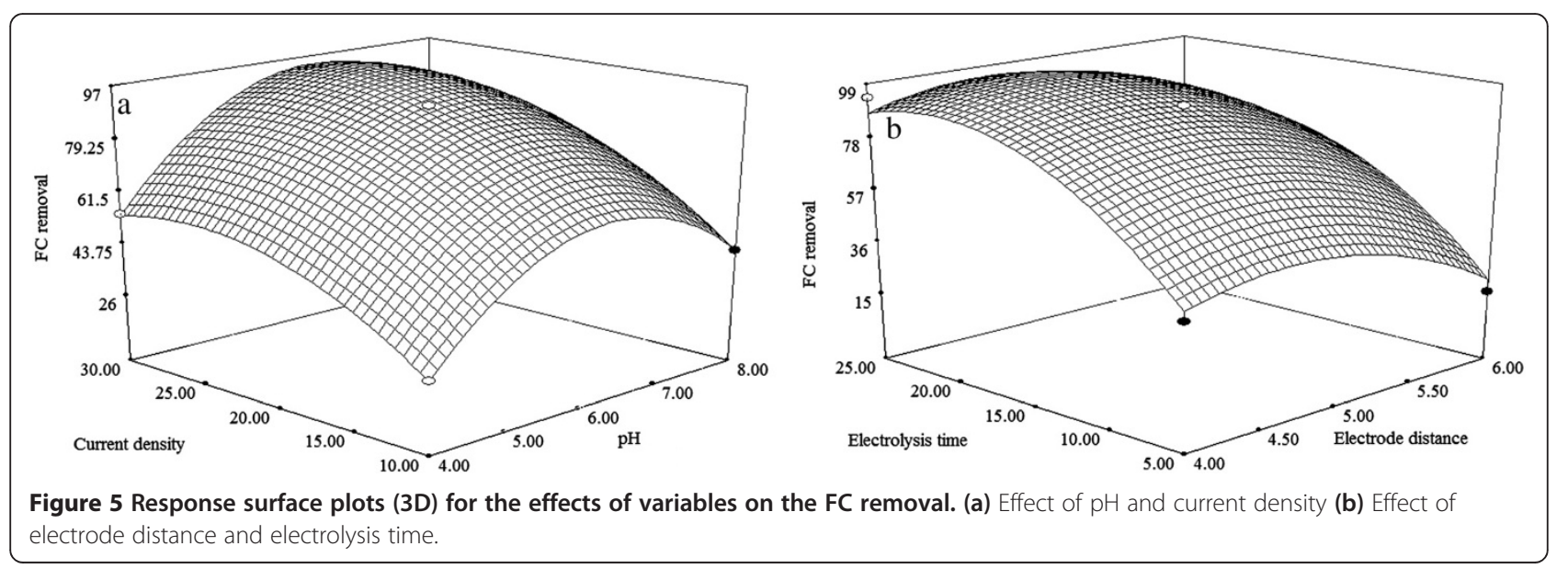




\section{Effect of electrolysis time}

Electrolysis time is of vital importance in the performance EC process. From the Figures $3 b, 4 b, 5 b$, it is found that, removal of efficiency of TS, COD and FC increases with increasing electrolysis time upto $15 \mathrm{~min}$, thereafter removal efficiency shows almost constant. It can be explained by the fact that electrolysis time increases, an increase occurs in the amount of metal hydroxide flocs $\left(\mathrm{M}(\mathrm{OH})_{3}\right)$ which promotes the removal of TS, COD and FC via a sweep coagulation followed by precipitation mechanism, thus removal effciencey of TS, COD and FC increased. Thereafter (15-30 min), almost all toxic matters are removed as flocs and hence no change in removal of TS, COD and FC removal with the increase in electrolysis time [22].

\section{Optimization}

In order to determine the optimum process parameters for maximum TS, COD and FC removal efficiencies, Derringer's desired function methodology optimization was used in this present study. This numerical optimization technique evaluates a point that maximizes the desirability function. According to BBD results, optimal operating conditions for the maximum removal of TS, COD and FC based on Derringer's desired function methodology is found to be initial $\mathrm{pH}$ of 7 , current density of $20 \mathrm{~mA} / \mathrm{cm}^{2}$, electrode distance of $5 \mathrm{~cm}$ and electrolysis time of $20 \mathrm{~min}$. Under these conditions, predicted removal efficiency of TS, COD and FC is found to be $99.87,95.47$ and $97.15 \%$ respectively. Experiments were performed under the optimized conditions, which shows the removal efficiency of TS, COD and FC close to predicted values (98.45, 94.75 and $96.34 \%$ respectively).

\section{Conclusions}

In this study, BBD was employed to study and optimize the process variables under different operating conditions such as initial $\mathrm{pH}$, current density, electrode distance and electrolysis time to treat grey wastewater by EC process using stainless steel electrode in batch mode. From the results, it was observed that, the operating variables have significant effects on the EC process. Quadratic mathamatical models were developed for predicting the removal of TS, COD and FC and optimum operating conditions was determined by Derringer's desired function methodology. The optimal conditions were found to be: initial $\mathrm{pH}$ of 7 , current density of $20 \mathrm{~mA} / \mathrm{cm}^{2}$, electrode distance of $5 \mathrm{~cm}$ and electrolysis time of $20 \mathrm{~min}$. Under these optimal operating conditions, the experimental removal efficiencies (98.45, 94.75 and $96.34 \%)$ was closely agreed with the predicted values (99.87, 95.47 and 97.15\%). These results indicated that EC process can be scale-up in large scale level to treat grey wastewater with high removal efficiency of TS, COD and FC.

\section{Competing interests}

The authors declare that they have no competing interests.

\section{Authors' contributions}

All authors read and approved the final manuscript.

\section{Acknowledgments}

The authors are thankful to University Grant Commission (F.No:39-853/2010), Government of India, for financial support to fabricate and use the experimental setup.

\section{Author details}

'Department of Food Technology, Kongu Engineering College, Perundurai Erode-638052, TN, India. ${ }^{2}$ Department of Food Technology, Kongu Engineering College, Perundurai Erode-638052, TN, India. ${ }^{3}$ Department of Food Technology, Kongu Engineering College, Perundurai Erode-638052, TN, India.

Received: 15 March 2013 Accepted: 20 November 2013

Published: 10 January 2014

\section{References}

1. Yi Jing C, Mei Fong C, Chung Lim L, Hassell DG: A review on anaerobic-aerobic treatment of industrial and municipal wastewater. Chem Eng J 2009, 155:1-18.

2. Eriksson E, Auffarth $K$, Eilersen AM, Henze M, Ledin A: Household chemicals and personal care products as sources for xenobiotic organic compounds in grey wastewater. Water SA 2003, 29:135-146.

3. Elmitwalli TA, Shalabi M, Wendland C, Otterpohl R: Grey water treatment in UASB reactor at ambient temperature. Water Sci Technol 2007, 55:173-180.

4. Shin HS, Lee SM, Seo IS, Kim GO, Lim KH, Song JS: Pilot-scale SBR and MF operation for the removal of organic and nitrogen compounds from greywater. Water Sci Technol 1998, 38:79-88.

5. Lesjean B, Gnirss R: Greywater treatment with a membrane bioreactor operated at low SRT and low HRT. Desalination 2006, 199:432-434.

6. Li Z, Gulyas H, Jahn M, Gajurel DR, Otterpohl R: Greywater treatment by constructed wetland in combination with $\mathrm{TiO}_{2}$-based photocatalytic oxidation for suburban and rural areas without sewer system. Water Sci Technol 2003, 48:101-106.

7. Bektas N, Akbulut H, Inan H, Dimoglo A: Removal of phosphate from aqueous solutions by electro-coagulation. J Hazard Mater 2004, 106:101-105.

8. Adhoum N, Monser L, Bellakhal N, Belgaied JE: Treatment of electroplating wastewater containing $\mathrm{Cu}^{2+}, \mathrm{Zn}^{2+}$ and $\mathrm{Cr}(\mathrm{VI})$ by electrocoagulation. J Hazard Mater 2004, B112:207-213.

9. Sridhar R, Sivakumar V, Prince Immanuel V, Prakash Maran J: Treatment of pulp and paper industry bleaching effluent by electrocoagulation process. J Hazard Mater 2011, 186:1495-1502.

10. Lai $\mathrm{CL}$, Lin SH: Treatment of chemical mechanical polishing wastewater by electrocoagulation: system performances and sludge settling characteristics. Chemosphere 2004, 54:235-242.

11. Kobya M, Can OT, Bayramoğlu M: Treatment of textile wastewaters by electrocoagulation using iron and aluminum electrodes. $J$ Hazard Mater 2003, B100:163-178.

12. Inan H, Dimoglo A, Şimşek H, Karpuzcu M: Olive oil mill wastewater treatment by means of electro-coagulation. Sep Purif Technol 2004, 36:23-31.

13. Prakash Maran J, Sivakumar V, Thirgananasambandham K, Sridhar R: Microwave assisted extraction of pectin from waste Citrullus lanatus fruit rinds. Carbohyd Polym 2014, 101:786-791.

14. Prakash Maran J, Sivakumar V, Thirgananasambandham K, Kandasamy S: Modeling and analysis of film composition on mechanical properties of maize starch based edible films. Int J Biol Macromol 2013, 62:565-573.

15. Thirugnanasambandham K, Sivakumar V, Prakash Maran J, Kandasamy S: Chitosan based grey wastewater treatment- a statistical design approach. Carbohyd Polym 2013, 99(2):593-600. 
16. Thirugnanasambandham K, Sivakumar V, Prakash Maran J: Application of chitosan as an adsorbent to treat rice mill wastewater-mechanism, modeling and optimization. Carbohyd Polym 2013, 97(2):451-457.

17. Thirugnanasambandham K, Sivakumar V, Prakash Maran J: Treatment of egg processing industry effluent using chitosan as an adsorbent. J Serb Chem Soc. doi:10.2298/JSC130201053T.

18. Thirugnanasambandham K, Sivakumar V, Prakash Maran J: Optimization of electrocoagulation process to treat biologically pretreated bagasse effluent-response surface analysis. J Serb Chem Soc. doi:10.2298/JSC130408074T.

19. Prakash Maran J, Sivakumar V, Thirgananasambandham K, Sridhar R: Response surface modeling and analysis of barrier and optical properties of maize starch edible films. Int I Biol Macromol 2013, 60:412-421.

20. Prakash Maran J, Sivakumar V, Thirgananasambandham K, Sridhar R: Degradation behavior of biocomposites based on cassava starch buried under indoor soil conditions. Carbohyd Polym 2014, 101:20-28.

21. Mahesh S, Prasad B, Mall ID, Mishra IM: Electrochemical degradation of pulp and paper mill waste water COD and color removal. Ind Eng Chem Res 2006, 45:2830-2839.

22. Thirugnanasambandham K, Sivakumar V, Prakash Maran J: Treatment of rice mill wastewater using continuous electrocoagulation technique: optimization and modelling. J Korean Chem Soc 2013. doi:10.5012/jkcs.2013.57.6.1.

doi:10.1186/2052-336X-12-29

Cite this article as: Karichappan et al:: Optimization of electrocoagulation process to treat grey wastewater in batch mode using response surface methodology. Journal of Environmental Health Sciences \& Engineering 2014 12:29.

\section{Submit your next manuscript to BioMed Central and take full advantage of:}

- Convenient online submission

- Thorough peer review

- No space constraints or color figure charges

- Immediate publication on acceptance

- Inclusion in PubMed, CAS, Scopus and Google Scholar

- Research which is freely available for redistribution 